\section{Regeneration of Spinach from Leaf Callus}

\author{
Jameel M. Al-Khayri', Feng H. Huang ${ }^{2}$, and Teddy E. Morelock ${ }^{3}$ \\ Department of Horticulture and Forestry University of Arkansas, \\ Fayetteville, AR 72701
}

Additional index words. Spinacia oleracea, micropropagation, tissue culture

Abstract. Callus, induced in the dark from leaf tissue of spinach (Spinacia oleracea L. cv. Fall Green) on Murashige and Skoog (MS) medium supplemented with (in mg-liter $\left.^{-1}\right) 2$ kinetin and 0.5 2,4-D regenerated shoots upon transfer to a medium containing 2 kinetin, 0.01 2,4-D, and 1 GA $_{3}$. Complete plants were established by stimulating rooting of the shoots with $1 \mathrm{mg}$ IBA/liter and transferring them to potting soil; survival was $60 \%$. Chemical names used: $\mathrm{N}$-(2-furanylmethyl)-1H-purin-6-amine (kinetin); 2;4-dichlorophenoxy acetic acid (2,4-D); gibberellic acid $\left(\mathrm{GA}_{3}\right)$; 1H-indole-3butanoic acid (IBA).

In the Chenopodiaceae, the only wellstudied in vitro callus-plant regeneration system is that of Beta vulgaris L. (Butenko et al., 1972; De Greef and Jacobs, 1979; Hussey and Hepher, 1978; Saunders and Shin, 1986). Recently, other species in the genus Beta have also been regenerated (Yu, 1989). In vitro shoot multiplication has been achieved from stem apices and lateral buds of Atriplex canescens (Wochok and Sluis, 1980). The only other example of callus differentiation in the Chenopodiaceae was reported by Neskovic and Radojevic (1973), who described the formation of adventitious buds from calli derived from seedling apical tips of spinach. Whole plants were not obtained.

Our paper describes a regeneration system for spinach based on calli induced from mature leaves. Plant regeneration from mature tissue (e.g., leaf) is a valuable tool for propagating field-selected plants for breeding purposes when the selection of desired characteristics can be made only near plant maturity. In spinach breeding programs, digging plants from selection plots and transferring them to greenhouses to make crosses in isolation is a common practice. Limited survival of the transplants in the greenhouse can be a serious problem. With the availability of a micropropagation system, the cumbersome process is avoided, and a leaf from a selected plant can be used to regenerate many plants and, subsequently, numerous seeds may

Received for publication 26 June 1990. Published with approval of the Director of Arkansas Agricultural Experiment Station. The cost of publishing this paper was defrayed in part by the payment of page charges. Under postal regulations, this paper therefore must be hereby marked advertisement solely to indicate this fact.

'Graduate Assistant.

${ }^{2}$ Associate Professor.

${ }^{3}$ Professor. be obtained. The survival of the original plant is no longer crucial because its genome is maintained in the regenerates. We used 'Fall Green', a recently released spinach cultivar possessing resistance to most major spinach diseases (Goode et al., 1988).

Callus induction. Explants were taken from

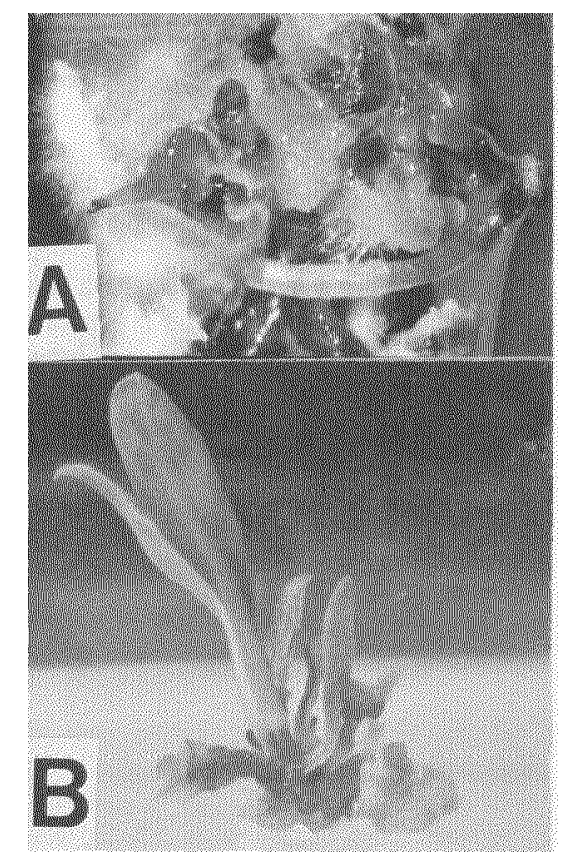

Fig. 1. Spinach plant regeneration. (A) Adventitious bud formation in spinach callus. (B) In vitro spinach shoots. (C) Rooting of shoots on IBA-free (right) and IBA-containing (left) medium. (D) A complete plantlet possessing root and shoot systems. (E) Spinach plantlet growing in potting soil. plants grown in a growth chamber held at a 10-h photoperiod $\left(350 \mu \mathrm{mol} \cdot \mathrm{s}^{-1} \cdot{ }^{-2}\right)$ and day/night cycles of 20/16C. Young leaves from 12-week-old plants were surface-sterilized in $70 \%$ ethanol for $30 \mathrm{sec}$ followed by immersion in $1 \%$ sodium hypochlorite $(20 \%$ Clorox) for $5 \mathrm{~min}$. Leaves were rinsed three times in sterile distilled water. Culture medium consisted of Murashige and Skoog (1962) inorganic salts (MS) supplemented with $0.4 \mathrm{mg}$ thiamine- $\mathrm{HCl} / \mathrm{liter}, 100 \mathrm{mg}$ myoinositol/liter, $3 \%$ sucrose, and $0.8 \%$ tissue culture-grade agar (Sigma, St. Louis). The $\mathrm{pH}$ was adjusted to 5.8 with $1 \mathrm{~N} \mathrm{NaOH}$. To induce callus, the medium contained $2 \mathrm{mg}$ kinetin/liter and $0.1,0.5$, or $1 \mathrm{mg} \mathrm{2,4-D/}$ liter. The medium was dispensed in $25 \times$ 150-mm culture tubes ( $15 \mathrm{ml} /$ tube) covered with plastic caps. All media were autoclave at $121 \mathrm{C}$ and $103 \mathrm{kPa}$ for $15 \mathrm{~min}$. One $5-\mathrm{mm}$ diameter leaf disk was cultured with the abaxial side down in each tube. Cultures were held at 20C in the dark or exposed to a 10$\mathrm{h}$ photoperiod of cool-white fluorescent light $\left(50 \mu \mathrm{mol} \cdot \mathrm{s}^{-1} \cdot \mathrm{m}^{-2}\right)$. The experiment was set up as a factorial design with 20 replications; light vs. dark and levels of 2,4-D were used as main effects. Five weeks later, fresh

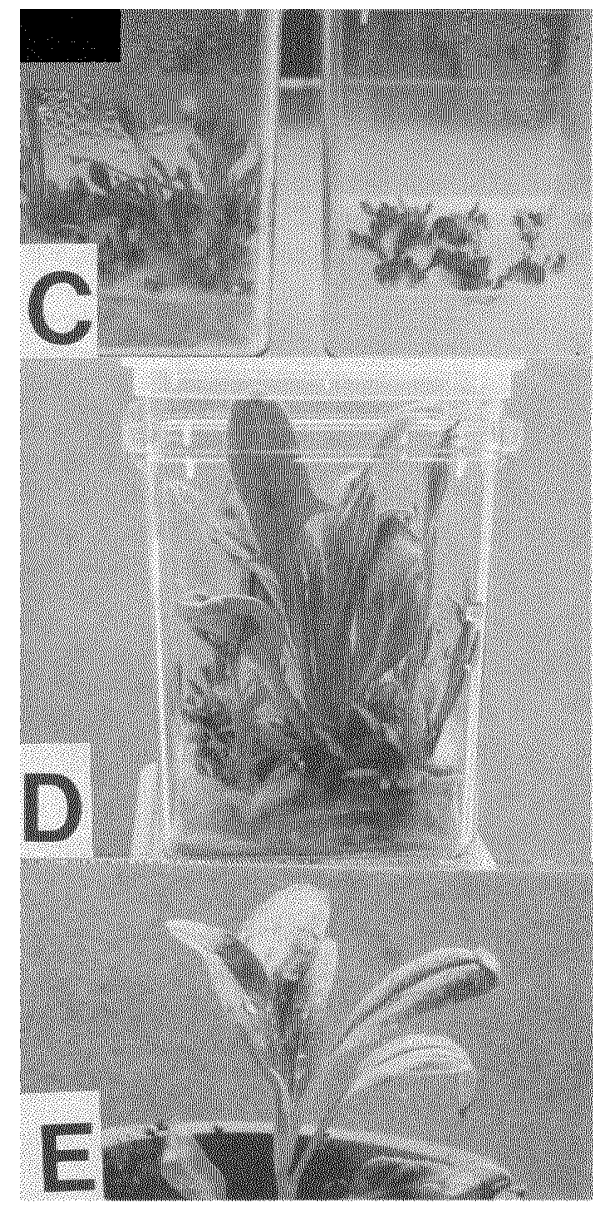


Table 1. Effect of light during incubation and 2,4-D concentration on callus fresh weight. ${ }^{z}$

\begin{tabular}{|c|c|c|c|}
\hline \multirow{3}{*}{$\begin{array}{l}\text { 2,4-D concn } \\
\left(\mathrm{mg} \cdot \text { liter }^{-1}\right)\end{array}$} & \multicolumn{3}{|c|}{$\begin{array}{l}\text { Mean callus } \\
\text { fresh wt }(\mathrm{g})\end{array}$} \\
\hline & \multicolumn{2}{|c|}{ Incubation ${ }^{y}$} & \multirow[b]{2}{*}{ Mean $^{x}$} \\
\hline & Light & Dark & \\
\hline 0.1 & 0.250 & 0.339 & 0.295 \\
\hline 0.5 & 0.323 & 0.437 & 0.380 \\
\hline 1.0 & 0.316 & 0.366 & 0.341 \\
\hline Meanw & 0.296 & 0.381 & \\
\hline
\end{tabular}

${ }^{2}$ Data are means (weight of callus/explant disk) of 20 observations.

${ }^{y_{L S D}}(5 \%)=0.049$ to compare mean calli weight in each treatment.

$\mathrm{x}_{\text {LSD }}(5 \%)=0.035$ to compare mean $2,4-\mathrm{D}$ concentrations.

${ }^{w} \operatorname{LSD}(5 \%)=0.029$ to compare mean light vs. dark.

weights of individual calli were measured with a digital microscale. Data were subjected to analysis of variance, and the means were separated by least significant difference. Similar results were obtained when the experiment was duplicated (data not shown); thus, the data presented pertain to a single experiment.

Shoot regeneration. Five weeks after culture initiation, calli were transferred onto regeneration medium. Because the optimum callus growth was obtained in the dark with $2 \mathrm{mg}$ kinetin/liter and $0.5 \mathrm{mg} \mathrm{2,4-D/liter}$, subsequent regeneration experiments were carried out only with calli induced using this treatment. The regeneration medium consisted of the same inorganic and organic constituents described above, augmented with 2 $\mathrm{mg}$ kinetin/liter; 0.0 , 0.01, or $0.05 \mathrm{mg}$ 2,4-D/liter; and $1 \mathrm{mg} \mathrm{GA}_{3} /$ liter. The medium was dispensed in $25 \times 150$-mm tubes, and each tube received one piece of callus. Cultures (18 calli randomly chosen per treatment) were maintained in the light. After 12 weeks on the same regeneration medium, we measured the number of regenerating callus pieces. The calli were subculture onto fresh medium of the same composition for further shoot multiplication.

Rooting and plant establishment. To induce rooting, 36 shoots of 1 to $3 \mathrm{~cm}$ were transferred into GA7 culture vessels (Magenta Corp.; Chicago) (six shoots/vessel) containing $50 \mathrm{ml}$ of MS medium solidified with $8 \mathrm{~g}$ agar/liter (same type as above) either free of growth regulators or supplemented with $1 \mathrm{mg}$ IBA/liter. Cultures were maintained at $20 \mathrm{C}$ and exposed to a 10-h photoperiod. After 4 to 6 weeks, plantlets were acclimated by opening the cover of the culture vessel slightly to gradually reduce humidity. Plantlets were then transplanted into peatlite growing medium (Fissurs Sunshine mix \#1, Vancouver, B.C., Canada), watered with 1/2-strength MS salts, and kept in clear plastic containers for 2 weeks before being placed in a greenhouse.

Callus induction. Callus proliferated from the cut edge of explants $(100 \%)$ within 10 days, regardless of the treatment, but the amount of callus produced was affected by the level of 2,4-D in the medium and by light. Dark incubation had a positive effect on callus production at all three concentrations of 2,4-D tested (Table 1). Explants incubated in darkness on a medium containing $0.5 \mathrm{mg} \mathrm{2,4-D/liter} \mathrm{produced} \mathrm{the} \mathrm{highest} \mathrm{cal-}$ lus weight. Therefore, regeneration studies and subsequent experiments were conducted using this treatment. A similar effect of 2,4-D was observed in light-induced callus; $0.5 \mathrm{mg} 2,4-\mathrm{D} /$ liter also resulted in the largest callus.

Shoot regeneration. Eight to 12 weeks after the calli were transferred onto a regeneration medium, adventitious budding was observed (Fig. 1A). When differentiating calli were subculture to a fresh regeneration medium, shoot formation and multiplication occurred (Fig. 1B). Subculturing at this stage is not required, but it is important when many plants are desired.

The presence of 2,4-D in the regeneration medium at $0.05 \mathrm{mg} \cdot$ liter $^{-1}$ inhibited callus differentiation. Reducing 2,4-D to 0.01 $\mathrm{mg} \cdot$ liter ${ }^{-1}$ resulted in $16.7 \%$ shoot formation from 18 calli cultured on regeneration medium, while omitting the 2,4-D resulted in $5.6 \%$ regeneration.

Rooting and plant establishment. On IBAfree medium, only $11 \%$ of the regenerated shoots rooted, producing a mean root length of $13 \mathrm{~mm}$. The addition of $1 \mathrm{mg}$ IBA/liter resulted in a substantial improvement in rooting. Sixty-seven percent of the regenerated shoots rooted (mean length of $52 \mathrm{~mm}$ ). The presence of IBA not only enhanced rooting but also encouraged more shoot growth
(Fig. 1C). Normal plant appearance was exhibited by the plantlets upon further growth on the medium (Fig. 1D). Only $60 \%$ of the regenerates transplanted to soil survived when exposed to a controlled environment held at 20C (Fig. 1E).

This study presents a system for the micropropagation of spinach from leaf explants. The immediate potential use of this system is the propagation of superior spinach plants selected in our breeding program to increase seed production and reduce the problems associated with digging the whole plants from the field. Our method for regeneration of spinach plants from callus satisfies an essential prerequisite for the use of somaclonal variation and plant transformation. Although this system resulted in plant regeneration, further studies with medium components such as sugar, vitamins, and organic substances may result in improved regeneration frequency and shorten the time required for regeneration.

\section{Literature Cited}

Butenko, R.G., A. Atanossov, and W. Urmantsera. 1972. Some features of the sugar beet tissue culture. Phytomorphology 22: 140-143.

De Greef, W. and M. Jacobs. 1979. In vitro culture of the sugarbeet: Description of a cell with high regeneration capacity. Plant Sci. Lett. 17:55-61.

Goode, M.J., T.E. Morelock, and J.L. Bowers. 1988. 'Fall Green' spinach. HortScience 23:931.

Hussey, G. and A. Hepher. 1978. Clonal propagation of sugar beet plants and the formation of polyploids by tissue culture. Ann. Bot. 42:477479

Murashige, T. and F. Skoog. 1962. A revised medium for rapid growth and bioassay with tobacco tissue cultures. Physiol. Plant. 15:473497.

Neskovic, M. and L. Radojevic. 1973. The growth of and morphogenesis in tissue cultures of Spinacia oleracea L. Bul. Inst. Jard. Bot., Univ. Beograd 8:35-37.

Saunders, J.W. and K. Shin. 1986. Germplasm and physiological effects on induction of highfrequency hormone autonomous callus and subsequent shoot regeneration in sugarbeet. Crop Sci. 26:1240-1245.

Wochok, Z.S. and C.J. Sluis. 1980. Gibberellic acid promotes Atriplex shoot multiplication and elongation. Plant Sci. Lett. 17:363-369.

Yu, M.H. 1989. Callus induction and differentiation from leaf explants of different species of the genus Beta. Crop Sci. 29:205-209. 